\title{
POPULATION CONDITIONS OF ECHINOIDEA AND CORAL REEF COVERS IN PONCAN GODANG ISLAND, SIBOLGA, NORTH SUMATERA
}

\author{
Nailul Adni ${ }^{1}$ *, Aras Mulyadi ${ }^{1}$, Thamrin ${ }^{1}$ \\ ${ }^{1}$ Department of Marine Science, Faculty of Fisheries and Marine Universitas Riau, Pekanbaru \\ *nailul.adni05@gmail.com
}

\begin{abstract}
Poncan Godang Island is included in the appropriate category based on the suitability of land for the Sibolga tourist area, with the presence of tourism activities that can also affect the amount of biodiversity in it. Considering the importance of coral reefs for biodiversity and sea urchins which also have a role in coral reef ecosystems, it is necessary to conduct research on the condition of sea urchins population and the percentage of coral reefs on Poncan Godang Island. Sea urchin and coral reef data were collected using the Line Intercept Transect (LIT) method by monitoring directly on the transect line along 50 meters. The results obtained indicate that the population of sea urchins in the waters of Poncan Godang Island, North Sumatra can be described, that sea urchins do not affect the coral reef ecosystem because at stations 1 and 5 there is no sea urchin and the percentage of coral cover is classified as bad, but at station 3 there are 32 individuals with coral reef cover conditions, while at stations with The percentage of good coral cover is that at station 4 there are only 25 individuals, as well as at station 2 where the percentage of coral cover is higher than station 3 and there are no sea urchins.
\end{abstract}

Keywords: Coral, Echinoidea, Diadema sitosum, Sea Urchin, Poncan Godang

\section{PENDAHULUAN}

Terumbu karang (coral reef) merupakan kelompok organisme yang hidup didasar perairan laut dangkal, terutama didaerah tropis. Terumbu karang merupakan ekosistem yang dibangun oleh biota laut penghasil kapur, terutama oleh hewan karang, bersama-sama dengan biota lain yang hidup didasar laut maupun kolom air. Hewan karang, yang merupakan penyusun utama terumbu karang, terdiri dari polip dan skeleton. Polip merupakan bagian lunak, sedangkan skeleton merupakan bagian yang keras. Pada bagian polip terdapat tentakel untuk menangkap plankton sebagai sumber makanannya. Setiap polip karang mengsekresikan zat kapur $\mathrm{CaCO}_{3}$ yang membentuk kerangka skeleton karang [1].

Bulu babi merupakan kelompok hewan lunak yang memiliki cangkang, dan tidak memiliki tulang belakang atau avertebrata [2]. Bulu babi dari kelas Echinoidea yang hidup di dunia diperkirakan sebanyak kurang lebih 800 jenis yang terbagi atas dua subkelas yaitu Perischoechinoidea dan Echinoidea, 15 ordo, dan 46 famili [3]. Di Indonesia, terdapat kurang lebih 84 jenis bulu babi yang berasal dari 31 famili dan 48 genus [4].

Menurut [5], bulu babi merupakan spesies kunci (keystone species) bagi komunitas terumbu karang, hal ini disebabkan bulu babi adalah salah satu 
hewan pengendali populasi makroalga. Jumlah populasi bulu babi pada perairan dapat memberi informasi bagaimana pengaruh kepadatan bulu babi terhadap kondisi terumbu karang yang ada di perairan Pulau Poncan Gadang.

Pulau-pulau yang berpotensi untuk pengembangan ekowisata bahari adalah Pulau Poncan Besar dan Pulau Poncan Kecil karena memiliki potensi terumbu karang untuk wisata selam dan snorkeling serta Pulau Pulau Poncan sudah memiliki fasilitas wisata seperti penginapan, restoran, dermaga, dan fasilitas lainnya [6].

Hasil penelitian [7] menunjukkan bahwa Pulau Poncan Besar dan Pulau Poncan Kecil termasuk ke dalam kategori sesuai berdasarkan kesesuaian lahan untuk kawasan wisata Sibolga, dengan adanya aktivitas wisata juga dapat mempengaruhi jumlah keanekaragaman hayati di dalamnya. Mengingat betapa pentingnya terumbu karang bagi keanekargaman hayati serta bulu babi yang juga memiliki peranan pada ekosistem terumbu karang maka perlu dilakukan penelitian untuk mengetahui kondisi, populasi bulu babi, persentase terumbu karang, dan pengaruh bulu babi terhadap kondisi tutupan terumbu karang di Pulau Poncan Godang.

\section{METODE PENELITIAN Waktu dan Tempat}

Penelitian ini dilaksanakan pada Maret 2020. Pengambilan data berlokasi di perairan Pulau Poncan Kecamatan Tapanuli Tengah Sibolga Sumatera Utara (Gambar $1)$.

\section{Metode Penelitian}

Metode yang digunakan adalah metode survey dengan mengumpulkan berupa data primer yang diperoleh dari hasil pengamatan langsung di lapangan dan data sekunder yang didapat dari studi literatur berupa buku, jurnal, makalah, artikel dan dari pihak terkait.

Penentuan titik stasiun ditentukan pada saat di lapangan berdasarkan purpossive sampling yaitu mempertimbangkan karakteristik lingkungan yang ada, pada penelitian ini menempatkan 5 titik stasiun (Gambar 1).

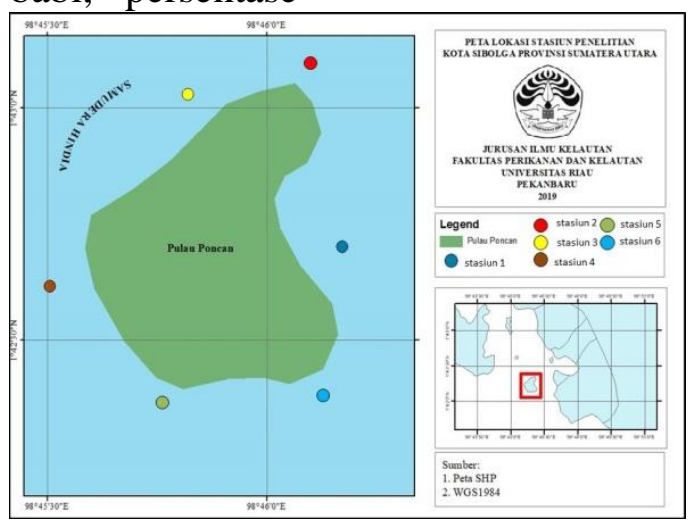

Gambar 1. Peta Lokasi Penelitian

Prosedur Penelitian

Pengambilan data dilakukan menggunakan metode Line Intercept Transect (LIT) dengan melakukan pemantauan secara langsung di garis transek sepanjang $50 \mathrm{~m}$. Transek yang digunakan untuk pengamatan kepadatan bulu babi adalah transek sama yang digunakan untuk pengamatan kondisi terumbu karang dengan areal pemantauan 2,5 meter di sisi kiri dan kanan line transek. Selanjutnya, jumlah bulu babi di sepanjang areal pemantauan dicatat jumlahnya, difoto untuk dokumentasi, kemudian dihitung kepadatannya. Untuk menganalisis tutupan terumbu karang maka di gunakan rumus persentase dari [8]. Rumus yang digunakan sebagai berikut: 
Keterangan:

$$
\mathrm{Ni}=\frac{\mathrm{li}}{\mathrm{L}} \times 100 \%
$$

$$
\begin{aligned}
& \mathrm{ni}=\text { tutupan terumbu karang }(\%) \\
& \mathrm{li}=\text { Panjang lifeform jenis ke-i } \\
& \mathrm{L}=\text { Panjang transek }
\end{aligned}
$$

Klasifikasi kondisi terumbu karang berdasarkan persentase penutupannya,

\begin{tabular}{|c|c|}
\hline Sangat Bagus & $75 \%-100 \%$ \\
\hline Bagus & $50 \%-74.9 \%$ \\
\hline Sedang & $25 \%-49.9 \%$ \\
\hline Buruk & $0 \%-24.9 \%$ \\
\hline
\end{tabular}
menurut Keputusan MENLH No 4 tahun 2001, tentang klasifikasi kondisi terumbu karang, sebagai berikut:

Hubungan antara kepadatan bulu babi dengan tutupan karang hidup dan tutupan karang mati dianalisis dengan analisis deskiptif.

\section{HASIL DAN PEMBAHASAN \\ Populasi Bulu Babi}

Hasil pengamatan bulu babi di setiap stasiunnya pada perairan Pulau Poncan Godang dapat dilihat (Tabel 1).

Tabel 1. Populasi Bulu Babi pada Perairan Pulau Poncan

\begin{tabular}{ccc}
\hline Jenis & Stasiun & Jumlah (ind) \\
\hline & 1 & 0 \\
Diadema & 2 & 0 \\
sitosum & 3 & 32 \\
& 4 & 25 \\
& 5 & 0 \\
\hline
\end{tabular}

Jenis bulu babi yang ditemukan hanya 1 jenis, yaitu Diadema sitosum yang terdapat pada stasiun 3 dan 4. Pada stasiun 3 terdapat 32 individu, sedangkan pada stasiun 4 hanya terdapat 25 individu, sedangkan pada stasiun 1, 2, dan 5 tidak ada bulu babi yang ditemukan.

\section{Kondisi Terumbu Karang}

Hasil Persentase tutupan terumbu karang hidup di setiap stasiun dapat dilihat pada Tabel 2.
Tabel 2. Kondisi Turumbu Karang Perairan Pulau Poncan Kota Sibolga Provinsi Sumatera Utara

\begin{tabular}{ccc}
\hline Stasiun & $\begin{array}{c}\text { Persentase } \\
\text { Tutupan (\%) }\end{array}$ & Kategori \\
\hline 1 & 5,00 & Buruk \\
2 & 43,80 & Sedang \\
3 & 30,40 & Sedang \\
4 & 51,80 & Baik \\
5 & 23,02 & Buruk \\
\hline Rata-rata & 30,80 & Sedang \\
\hline
\end{tabular}

Kondisi tutupan terumbu karang pada perairan Pulau Poncan tergolong kedalam kategori sedang dengan rata-rata persentase tutupan terumbu karang sebesar 30,80\%. yaitu pada stasiun 1 hanya terdapat tutupan karang sebesar 5,00\% dengan kategori buruk, pada stasiun 2 sebesar 43,80\% dengan kategori sedang, sedangkan pada stasiun 3 sebesar $30,40 \%$ dimana persentase tutupan lebih rendah dari stasiun 2 namun masih termasuk dalam kategori sedang, pada stasiun 4 persentase tutupan karangnya sebesar $51,80 \%$ dengan kategori baik, namun pada stasiun 5 persentase sebesar 23,02\% dengan kategori sedang, dimana tutupan terumbu karang mengalami penurunan.

Rendahnya persentase tutupan terumbu karang hidup pada stasiun 1 dan 5 disebabkan karena adanya aktifitas nelayan disekitar stasiun yang lepas dari pengawasan pemerintah dan kurangnya kesadaran masyarakat sekitar ataupun nelayan itu sendiri akan pentingnya menjaga kondisi perairan untuk kedepannya. Nelayan yang melakukan aktivitas penangkapan di daerah perairan Pulau Poncan Godang Kota Sibolga Provinsi Sumatera Utara menggunakan alat tangkap yang ilegal yaitu menggunakan bom menurut penjaga resort di pulau poncan,. Hal ini menyebabkan ekositem di perairan sekitar Pulau Poncan terganggu termasuk terumbu karang dan ikan karangnya. 
Pada masing-masing stasiun penelitian juga di temukan substrat dasar berupa Sand (SD) berkisar antara 4\%51,3\%. [9] menyatakan bahwa, tingginya nilai sand (SD) pada suatu perairan akan mengakibatkan tutupan Hard Coral (HC) tidak merata. Hal ini juga didukung oleh pernyataan [10] yang menyatakan bahwa substrat dasar sand memiliki kandungan kalsium karbonat sedikit daripada kandungan yang terdapat di patahan karang yang berasal dari pelapukan maupun koloni karang, sehingga sedikit larva yang mampu bertahan hidup pada substrat tersebut.

\section{Pengaruh Populasi Bulu Babi dengan Tutupan Terumbu Karang}

Dari hasil pengambilan data dapat dilihat bahwah tutupan terumbu karang dengan kategori baik memiliki jumlah bulu babi yang lebih sedikit dibandingkan dengan stasiun dengan persentase tutupan karang sedang (Gambar 2).

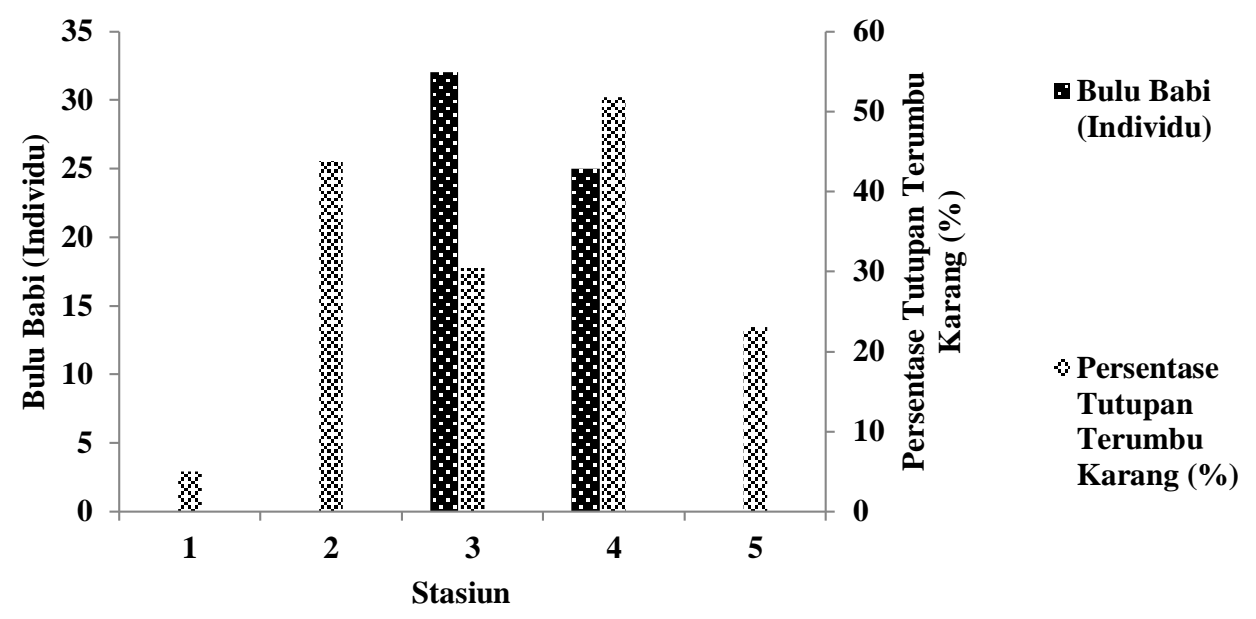

Gambar 2. Pengaruh Populasi Bulu Babi dengan Tutupan Terumbu Karang

Bulu babi pada perairan Pulau Poncan Godang tidak memberikan pengaruh terhadap kondisi terumbu karang disana dikarenakan, stasiun 1 memiliki persentase tutupan terumbu karang paling sedikit dan tidak ada bulu babi yang ditemukan disana, pada stasiun 2 tutupan terumbu karang termasuk kedalam kategori sedang namun juga tidak terdapat bulu babi pada stasiun ini, sedangkan pada stasiun 3 jumlah bulu babi yang di temukan adalah yang terbanyak di bandingkan dengan stasiun lainnya namun persentase tutupan terumbu karangnya lebih kecil dibandingkan stasiun 2 dan 4, pada stasiun 4 juga ditemukan bulu babi namun jumlahnya lebih sedikit dibandingkan stasiun 3 sedangkan jumlah persentase tutupan terumbu karang pada stasiun ini tergolong dalam kategori baik, kondisi stasiun 5 tidak jauh berbeda dengan stasiun
1 dikarenakan pada stasiun ini juga tidak ditemukan bulu babi dan kodisi tutupan terumbu karangnya juga dalam kategori sedang.

Hal ini sesuai dengan penelitian yang dilakukan oleh [11] kepadatan bulu babi lebih banyak ditemukan pada kondisi terumbu karang kategori rendah sampai sedang, sedangkan pada kondisi terumbu karang yang sangat buruk, baik dan sangat baik kepadatan bulu babi akan sangat berkurang

\section{KESIMPULAN DAN SARAN Kesimpulan}

Pada Perairan Pulau Poncan Godang dapat dikatakan bahwa populasi bulu babi tergolong sangat rendah di karenakan dari kelima stasiun hanya stasiun 3 dan 4 yang ditemukan bulu babi dengan jumlah 62 individu. 
Pulau Poncan memiliki persentase tutupan karang berkisar antara 5-51,8\% dengan nilai rata-rata $30,80 \%$, termasuk dalam kategori sedang, dengan kondisi tutupan terumbu karang terendah terdapat pada stasiun 1 ,dan kondisi paling tinggi yaitu pada stasiun 4, tingginya persentase tutupan terumbu karang pada stasiun 4 juga di karenakan oleh adanya terdapat bulu babi sebagai pengatur populasi alga yang dapat merusak terumbu karang jika pertumbu hannya terlalu besar.

Bulu babi tidak memberikan pengaruh terhadap kondisi tutupan terumbu karang pada perairan Pulau Poncan Gadang dikarenakan bulu babi yang ditemukan hanya sedikit dan tidak pada semua stasiun ditemukan bulu babi

\section{Saran}

Bedasarkan hasil penelitian ini bulu babi memang tidak memberikan pengaruh yang nyata terhadap kondisi tutupan terumbu karang, namun juga terdapat faktor-faktor lainnya yang mempengaruhi terumbu karang, maka dari itu perlu diadakannya penelitian lanjutan mengenai faktor-faktor lain yang dapat mempengaruhi kondisi terumbu karang, agar terumbu karang dapat terjaga kelestariannya.

\section{DAFTAR PUSTAKA}

1. Giyanto. A,M., T.A. Hadi, B. Agus, H. Muhammad, S. Abdullah, dan Y.I. Marindah. (2017). Status Terumbu Karang Indonesia 2017. Jakarta.

2. Radjab, A.W., A.S. Khouw, J.W. Mosse, dan P.A. Uneputty. (2010). Pengaruh Pemberian Pakan terhadap Pertumbuhan dan Reproduksi Bulu Babi (Tripneustes gratilla L) di Laboratorium. Pusat Penelitian Oseanografi dan Pusat Penelitian Limnologi-LIPI.

3. Aziz, A. (1993). Beberapa Catatan Tentang Perikanan Bulu Babi. Balai Penelitian Biologi Laut. Pusat Penelitian dan Pengembangan Oseanologi-LIPI. Jakarta

4. Clark, A.M. and F.W.E. Rowe. (1971). Monograph of Shallow Water Indo-west Pacific Echinoderms. London, Trustees of British Museum: 171-210.

5. Nystrom, M., C. Folke., F. Moberg. (2000). Coral Reef Disturbance and Resilience in A Human-Dominated Environment. Trends in Ecology and Evolution

6. Dinas Pariwisata Kota Sibolga. (2004). Selayang Pandang Kota Sibolga. 2004. Sibolga.

7. Sitanggang, L.P. (2006). Studi Pemanfaatan Ruang untuk Pengembangan Pariwisata di Kawasan Pesisir Sibolga. Sekolah Pascasarjana IPB. Bogor

8. Gomez, E. D. and H. Yap. (1984). Monitoring Reef Condition. dalam Kenchington, R.A. and B. Hudson E.T. (ed). Coral Reef Management Hand Book. Unesco Regional Office for Science and Technology for South East Asia. Jakarta, 187-195 pp.

9. Pranata, N.B., Muliadi, dan A,S.S. Sanova. (2018). Kondisi Ekosistem Terumbu Karang di Teluk Cina, Pulau Lemukutan, Kalimantan Timur. Jurnal Laut Khatulistiwa, 1(2): 9-16.

10. Prasetyo, A.B.T., L.P.S. Yuliadi, S. Astuty, D.J. Prihadi. (2018). Keterkaitan tipe substrat dan laju sedimentasi dengan kondisi tutupan terumbu karang di Perairan Pulau Panggang, Taman Nasional Kepulauan Seribu. Perikanan dan Kelautan, 9(2): 1-7

11. Thamrin, Setiawan, S.J., dan Siregar, S.H. (2011). Analisis Kepadatan Bulu Babi Diadema Setosum pada Kondisi Terumbu Karang Berbeda di Desa Mapur Kepulauan Riau. Jurnal Ilmu Lingkungan 